\title{
Editorial
}

\section{El futuro de la artroscopia de muñeca está aquí}

\author{
Pedro J. Delgado ${ }^{10}$ \\ ${ }^{1}$ Jefe de Servicio de Cirugía Ortopédica y Traumatología, Jefe de \\ Unidad de Cirugía de la Mano y Microcirugía, Hospital Universitario \\ HM Montepríncipe, Hospital Universitario HM Nuevo Belén, \\ Universidad San Pablo CEU, Boadilla del Monte, Madrid, España
}

Rev Iberam Cir Mano 2019;47:75-76.

En cirugía de la mano, la artroscopia de muñeca es una de las áreas que más ha evolucionado en los últimos 10 años. Desde que Terry Whipple realizara en el año 1986 la primera artroscopia de muñeca y el primer taller de trabajo para demostrar sus ventajas, esta técnica se ha desarrollado a un ritmo realmente vertiginoso.

Se ha avanzado mejorando los sistemas de tracción, con nuevas ópticas e instrumentales específicos, el desarrollo de la artroscopia seca y nuevos portales por los que prácticamente se puede acceder hoy en día a todos los compartimentos y estructuras de la muñeca.

Los esfuerzos en promoción y formación en artroscopia de muñeca son cada vez más numerosos. En 2005 se creó la European Wrist Artroscopy Society (EWAS) con los primeros cursos de formación en cadáver en el IRCAD de Estrasburgo y desde entonces, no paran de celebrarse cada vez más cursos, congresos y jornadas de formación, sin contar con que hoy en día es imposible organizar cualquier congreso nacional o internacional (SECOT, EFORT, FESSH, IFSSH) que no cuente con mesas especificas de artroscopia de muñeca.

El desarrollo es imparable. Tanto es así, que este año la EWAS decidió cambiar su denominación y ha pasado de "Sociedad Europea" a Sociedad Internacional de Artroscopia de Muñeca (International Wrist Arthroscopy Society, IWAS) motivada por el crecimiento mundial e incremento de asociados de fuera de Europa con interés en la artroscopia de muñeca. Cada año se describen nuevas técnicas y hoy en día podemos tratar la inmensa mayoría de las patologías articulares de muñeca utilizando el artroscopio.

En los últimos años España ha contribuido sustancialmente al desarrollo y expansión de las técnicas de artroscopia de muñeca. Francisco del Piñal (socio fundador y expresidente de IWAS) desarrolló la artroscopia seca, describió numerosas técnicas y editó libros dedicados a tratamiento artroscópico de las fracturas de radio distal y lesiones de la articulación radiocubital distal, que han formado e inspirado una nueva escuela de cirujanos españoles especializados en artroscopia de muñeca que han dado lugar a numerosas aportaciones, como las técnicas de ligamentoplastia escafolunar artroscópica para la inestabilidad escafolunar o el portal central volar descritas por Fernando Corella (ex-director de RICMA); las técnicas de capsulodesis dorsal escafolunar y ligamentoplastia radiocubital distal de Vicente Carratalá (director de RICMA), los estudios sobre seguridad y técnicas de propiocepción en artroscopia de muñeca de Mireia Esplugas, el tratamiento de la artrosis STT por Joaquim Casañas (presidente de SECMA), el tratamiento de las fracturas de escafoides asistido por artroscopia de Cristóbal Martínez, así como nuestras aportaciones en fracturas y tratamiento de la pseudoartrosis de escafoides.

Pero este espíritu innovador no queda solo ahí. En Brasil, destacan las nuevas técnicas en artroscopia de muñeca y cirugía mínimamente invasiva de Gustavo Mantovani (Sao Paulo) que fue presidente de IWAS y director de los cursos de artroscopia del IRCAD de Barretos, junto a los trabajos de Marcio Aita (Sao Paulo) en reconstrucción de ligamentos radiocarpianos y Ricardo Kaempf (Porto Alegre) de la articulación trapeciometacarpiana. En Argentina, las técnicas de fijación escafolunar con tornillo canulado (ARASL) y de pseudoartrosis de escafoides de Martín Caloia (Buenos Aires), miembro activo de IWAS y actual presidente de la AACM, los trabajos de investigación de Gabriel Clembosky, Gustavo Gómez y el maestro Carlos Zaidemberg, pionero de artroscopia de muñeca en Argentina. En Chile, con la escuela de técnicas avanzadas del equipo que dirige René Jorquera (Santiago) y los numerosos aportes de muchos cirujanos de mano de Colombia, México, Venezuela y Perú.

Y no solo ello, las jornadas y cursos dedicados a formación son cada vez más numerosos. Sólo en nuestro país se organizan más de seis cursos sobre artroscopia de muñeca al año y fuera de España, existen cursos de formación en el IRCAD de Barretos (Brasil), Buenos Aires y Santiago (Chile) y, a pesar de todo, no se da abasto a la demanda creada por el atractivo creciente en la artroscopia de muñeca.

Y el grado de colaboración e intercambio de ideas es impresionante, con grupos de trabajo creados para compartir experiencias y crear nuevas técnicas entre
Address for correspondence Dr. Pedro J. Delgado, Hospital DOI https://doi.org/ Universitario HM Montepríncipe, Avda. Montepríncipe, 25, Boadilla del Monte, Madrid, 28660, España (e-mail: pedrojdelgado@me.com).
Copyright $\odot 2019$ Thieme Revinter Publicações Ltda, Rio de Janeiro, Brazil

\section{License terms}

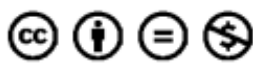


cirujanos de España y Latinoamérica. Se realizan publicaciones multicéntricas, muchas de ellas en nuestra revista, órgano de expresión de la cirugía de la mano en español y portugués. Se organizan mesas multinacionales de los países iberolatinoamericanos dedicadas a la artroscopia de muñeca, como en el pasado Congreso Sudamericano de Cirugía de Mano organizado por la Sociedad Colombiana de Cirugía de Mano (ASOCIMANO) en Cartagena (Colombia) y como el que tendrá lugar el año que viene en Maceió (Brasil) en el XIII Congreso Iberolatinoamericano de Cirugía de Mano (ILA) que organiza el Dr. Ricardo Kaempf, con Italia (país vecino mediterráneo) como país invitado.

El interés suscitado y desarrollo de las técnicas artroscópicas en España y Latinoamérica es imparable y crece cada día más, probablemente más que en resto del mundo. Aunque los orígenes y desarrollo industrial procedan de Estados Unidos, si bien Europa fue la que creó las bases científicas y formativas, el desarrollo y el talento está en España y Latinoamérica.

Por todo ello, el futuro de la artroscopia de muñeca está aquí.

Pedro J. Delgado

Editor Internacional de la Revista Iberoamericana de Cirugía de Mano (RICMA)

Secretario de la Sociedad Española de Cirugía de Mano (SECMA)

Conflicto de Intereses

Los autores del trabajo declaran no tener ningún conflicto de intereses. 